\title{
Pozebe v Primorju z vidika uspevanja mediteranskih kultur
}

\author{
Darko Ogrin \\ Dr., Oddelek za geografijo, Filozofska fakulteta, Univerza v Ljubljani, \\ Aškerčeva 2, 1000 Ljubljana, Slovenija \\ e-mail: darko.ogrin@ff.uni-lj.si
}

\section{Izvleček}

Klimatske značilnosti JZ Slovenije se približujejo sredozemskim, zato tu še uspevajo nekatere kulture, najpomembnejša je oljka, ki so značilne za osrednji Mediteran. Te kulture rastejo na njihovi severni klimatski meji, zato jih ogrožajo občasne pozebe. Razvoju oljkarstva in tudi drugih klimatsko zahtevnejših kultur gredo na roke tudi klimatski trendi $v$ zadnjih desetletjih in napovedi za 21. stoletje, ko naj bi se podnebje še otoplilo.

Ključne besede: Oljkarstvo, paleoklima, pozebe, topoklima, Slovenska Istra, Primorje, Slovenija

\section{Frosts in Primorska Region from the Aspect of Climatically More Sensitive Cultures}

\begin{abstract}
Climatic characteristics in south-west Slovenia are akin to the Mediterranean ones, therefore some more sensitive cultures still grow there; by far the most important is olive which is otherwise typical of the central Mediterranean. These cultures grow at their northern climatic borders, therefore they are periodically affected by severe frosts. The development of olive growing, and other climatically more sensitive cultures as well, has also been fostered by both the climatic trends of the last decades and the forecasts for the 21 st century prognosticating further warming of the climate.
\end{abstract}

Key words: Olive growing, Paleoclimate, Frosts, Topoclimate, Slovenian Istria, Primorska region, Slovenia 


\section{UVOD}

JZ del Slovenije, ki je reliefno odprt proti Tržaškemu zalivu in Sredozemlju, ima milejše klimatske razmere v primerjavi s pokrajinami v notranjosti Slovenije. $Z$ vidika uspevanja klimatsko zahtevnejših kultur so pomembne predvsem višje temperature (še posebej zimske in jesenske) in najdlje trajajoče sončno obsevanje. Splošne klimatske poteze se približujejo sredozemskim (slika 1), zato tu uspevajo nekatere kulture, ki so sicer značilne za osrednji Mediteran, npr. oljka, figa, mandljevec, granatno jabolko idr. Od teh je daleč najpomenejša oljka.

Nasadi oljk v Slovenski Istri in manjši nasadi te kulture v Goriških Brdih in Vipavski dolini ter nekatera rastišča $\mathrm{v}$ severni Italiji (Treviška pokrajina, severnoitalijanska jezera), so na enem najsevernejših območij, do koder oljke še uspevajo in je njihovo gojenje gospodarno. Kakovost oljčnega olja je na severni klimatski meji boljša, zato je večja tudi njegova tržna vrednost. Neugodna stran pa je večja nevarnost pozeb zaradi vdorov hladnega zraka. Če so pozebe prepogoste, lahko postane gojenje zaradi visokih stroškov obnove nasadov in izpada dohodka nerentabilno. Morebitna opustitev oljkarstva oziroma nazadovanje, kar se je v preteklosti pri nas po pozebah že dogajalo, ne bi imelo samo negativnih ekonomskih učinkov, ampak bi povzročilo veliko škodo tudi pri ohranjanju kulturne pokrajine. Precejšen delež kmetijskih površin, ki je bil v zadnjih dveh desetletjih intenzivnega obnavljanja oljčnikov rekultiviran, bi se zaradi specifične poklicne in socialne strukture oljkarjev, kjer je za večino oljkarstvo le dopolnilna dejavnost, in manjše primernosti za druge kmetijske kulture ponovno zarastel.

V zadnjih desetletjih, zlasti po letu 1980, doživlja oljkarstvo v Slovenski Istri velik razmah. Oljčniki zavzemajo skoraj 1200 ha, v njih raste več kot 300.000 dreves, oljkarji pridelajo 2000 do 2200 t plodov, iz katerih iztisnejo okoli $400 \mathrm{t}$ olja. Zaradi naraščanja povpraševanja po kvalitetnem domačem olivnem olju na slovenskem tržišču (sedanja proizvodnja pokrije manj kot polovico potreb), intenzivnega širjenja oljke, vsako leto zasadijo 30 do 50 dodatnih hektarjev, in ponovnega vračanja oljke $\mathrm{v}$ predele, kjer je $\mathrm{v}$ preteklosti sicer že bila, a so jo pozebe "potisnile« proti morju, se postavlja vprašanje, kakšne so splošne geoekološke možnosti za še nadaljno širitev in kakšne omejitve postavlja klima. Eno zanimivejših vprašanj pa je, kako planirati razvoj oljkarstva in tudi drugih mediteranskih kultur $\mathrm{z}$ vidika napovedanih klimatskih sprememb. 
Slika 1: Podnebni tipi v Sloveniji in razmerje med padavinami in temperaturami v Submediteranski Sloveniji.

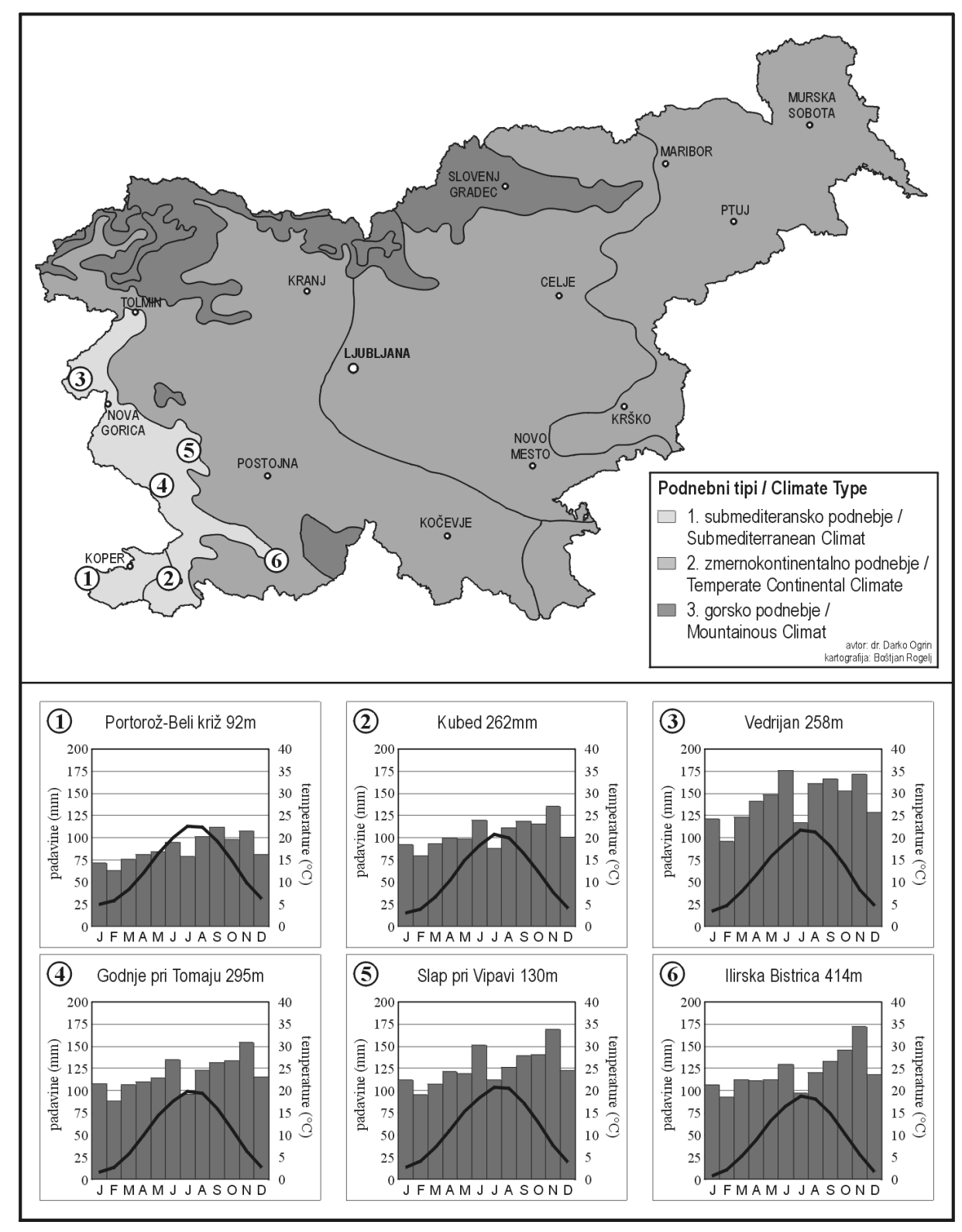




\section{MEDITERANSKE KULTURE V PRIMORJU}

Značilnost kmetijstva v Primorju je pestrost kultur, kjer prihaja do prepletanja kultur značilnih za celinsko Evropo (npr. jabolka in slive v Brkinih in dolini Notranjske reke), z bolj toplotno zahtevnimi $\mathrm{v}$ predelih $\mathrm{z}$ ugodnimi klimatskimi in mikroklimatskimi razmerami. V Slovenski Istri, v Brdih, ponekod v Vipavski dolini in nižjih predelih Krasa uspevajo oljka, figa, mandelj, granatno jabolko, žižola, japonska nešplja, aktinidija, v najbolj ugodnih legah tudi mandarina. Naštete vrste, razen oljke in v manjši meri aktinidije, nimajo večjega ekonomskega pomena.

Oljka raste na okoli 1200 ha, od tega jih je okoli 10 ha v Goriških Brdih in spodnji Vipavski dolini, kamor se vrača po pozebi leta 1929, vsi ostali so v Slovenski Istri. Kot tipična sredozemska kultura ne uspeva v celotni Slovenski Istri, ampak le $\mathrm{v}$ priobalnem pasu in gričevju do nadmorske višine 250 , redkeje $300 \mathrm{~m}$. Ni je tudi na naplavinah vodotokov, kjer so zanjo neustrezni talni in klimatski pogoji (pojav temperaturne inverzije). V notranjost sega le po prisojnih pobočjih Rižane, Osapske reke, Badaševice, Drnice, Dragonje in Rokave. Raziskava v Rižanski dolini je pokazala, da ima 70 \% oljčnikov južno ali zahodno ekspozicijo in $18 \%$ vzhodno ter da je $82 \%$ rastišč v višinskem pasu do $250 \mathrm{~m}$.

Največ nasadov je v zahodnem, nekoliko nižjem delu Slovenske Istre, zahodno od črte Škofije-Marezige-Koštabona. Po podatkih popisa prebivalstva in gospodinjstev iz leta 1991 je v krajevnih skupnostih (KS) v tem delu, če ne upoštevamo mestnih KS, rastlo skoraj $75 \%$ vseh oljk, od tega več kot $20 \% \mathrm{v}$ KS Lucija in Šmarje.

Oljkarstvo je postalo v Istri pomembno za časa Rimljanov. Razcvetelo se je v času Beneške republike. Sorazmerno veliko oljk je bilo tudi še v začetnem obdobju avstrijske vladavine v Istri, ko je bilo uzakonjeno pravilo obvezne vzgoje določenega števila oljčnih sadik za vsakega mladoporočenca. Tako je število oljk ostalo v sorazmerju z rastjo prebivalstva (Razvoj pridelovanja ..., 1985).

Z razvojem vinogradništva $\mathrm{v}$ drugi polovici 19. stoletja je začelo oljkarstvo nazadovati. Hud udarec mu je zadala pozeba 1929, ko se je število dreves zmanjšalo s 300.000 na 120.000 . Po političnih in družbenih spremembah po 2. svetovni vojni, z delno zamenjavo prebivalstva in močno deagrarizacijo in depopulacijo zaledja Slovenske Istre, se je število dreves zmanjšalo na 50.000 do 60.000. Oljke je močno prizadela tudi pozeba 1956. V osemdesetih letih 20. stoletja se je začela obnova oljčnikov, ki jo je delno zavrla pozeba 1985. Kljub temu se je do leta 1990 število dreves zvečalo na okoli 126.000 , od tega jih je bilo $90.000 \mathrm{v}$ ekstenzivnih in $36.000 \mathrm{v}$ intenzivnih nasadih (Vesel, Sedmak, 1990). Rahel zastoj v razvoju je pomenila tudi zadnja večja pozeba leta 
1996, ki je prizadela predvsem mlade oljke (Ogrin, 1997), ni pa zavrla širitve, saj se je oljka z več kot 300.000 drevesi povzpela na četrto mesto v Sloveniji takoj za jablano, breskvo in hruško.

Oljčniki so zasebni. Posamezniki imajo manjše površine (od 0,2 do 3 ha). Tudi kompleksi, kjer rastejo oljke, so manjši, največji meri približno 14 ha. V novih nasadih prevladuje avtohtona sorta istrska belica (50 do $70 \%$ ), ki je dobro rodna in oljevita ter dobro prenaša pozebo. Ker je za boljšo harmoničnost olivnega olja potrebnih več sort, sadijo še leccino (20 do $30 \%$ ), v starejših nasadih pa so še druge sorte: pendolino, frantoio, moraiolo, štorta, buga, črnica, drobnica, mata idr. (Vesel, 1996).

\subsection{Klimatski pogoji za oljkarstvo}

V Evropi so nasadi oljk na obrobju Sredozemskega morja z robnimi morji in se večinoma raztezajo med 30 in $35^{0}$ SGŠ. Najbolje uspevajo v sredozemskem podnebju z milimi zimami in ne pretoplimi poletji. Je kserofit, zato dobro prenaša sušo. Uspeva tudi na območjih s 300 do $500 \mathrm{~mm}$ padavin; za normalno rodnost jih mora pasti vsaj $130 \mathrm{~mm}$ od februarja do maja in 50 do $70 \mathrm{~mm}$ od julija do septembra. Večja količina padavin (nad $1000 \mathrm{~mm}$ ) ji ne škodi, toda le, če so tla dovolj prepustna. Glede prsti je zelo nezahtevna. Uspeva v suhih, peščenih in kamnitih prsteh, le da so dovolj prepustne in imajo dovolj kalcija (Sancin, 1990).

Zaradi severne lege (Submediteranska Slovenija leži nad $45^{\circ}$ SGŠ) in omiljenega vpliva sredozemskega podnebja so klimatski pogoji za uspevanje oljke pri nas mejni. Glavni omejevalni dejavnik so zimske minimalne temperature. Po Sancinu (1990) prenese oljka med zimskim mirovanjem - 13 do $-15{ }^{0} \mathrm{C}$, odvisno od zračne vlage, sorte, prehranjenosti rastline, njene starosti ipd. Oljka prej pozebe, če je mraz dlje časa in je vlažnost ozračja večja. V krajšem obdobju lažje prenese ohladitve s suhim vremenom in temperaturami -13 do $-15{ }^{0} \mathrm{C}$, kot pa daljše ohladitve s temperaturami -5 do $-8{ }^{0} \mathrm{C}$ in visoko vlažnostjo. Veliko bolj so občutljive mlade rastline.

Nevarnost poškodb zaradi mraza je večja, kadar se je vegetacija že začela ali še traja. Tedaj so lahko usodne že temperature od -2 do $-3{ }^{0} \mathrm{C}$. Nevarne so zlasti zgodnje spomladanske otoplitve in poznejše hitre in močne ohladitve, ko se v rastlini že začnejo asimilacijski procesi. Okvirno se prve poškodbe listov in vejic pojavijo pri $-8{ }^{0} \mathrm{C}$, večjih vej in debla pri -10 do $-12{ }^{\circ} \mathrm{C}$. Če mraz traja dlje časa, deblo pozebe pri $-14 \mathrm{do}-16{ }^{0} \mathrm{C}$. Toda tudi pri takih temperaturah koreninski vrat ni nikoli poškodovan, zato oljke spomladi poženejo iz njega (Sancin, 1990). 
Na splošno se temperature $\mathrm{v}$ Primorju znižujejo od obale proti višji notranjosti, zato je večja nevarnost pozebe v notranjosti. Ob obali Slovenske Istre so povprečne januarske temperature okoli $4{ }^{0} \mathrm{C}, \mathrm{v}$ gričevnati notranjosti, $\mathrm{v}$ večjem delu Krasa, Vipavske doline in Goriških brd pa med 2 in $4{ }^{\circ} \mathrm{C}$. Povprečne minimalne januarske temperature so $\mathrm{v}$ obalnem pasu pozitivne, $\mathrm{v}$ notranjosti pa že negativne. Nevarnost pozebe je večja tudi pri dnu dolin, kjer so ob anticiklonalnem vremenu ponoči izrazite temperaturne inverzije. Po meritvah v Slovenski Istri so lahko trenutne temperaturne razlike med predeli pod inverzno plastjo zraka in predeli nad njo v dolinah bližje morju med 3,5 in $5{ }^{\circ} \mathrm{C}$, v notranjosti do $8{ }^{0} \mathrm{C}$, izjemoma tudi več (Ogrin, 1995).

Analiza temperaturnih podatkov za meteorološko postajo Portorož $(92 \mathrm{~m}$ n.v.) ob morju in Kubed (262 m n.v.) v notranjosti Slovenske Istre, do koder oljke še sežejo, je pokazala, da sta bila ob pozebi januarja in februarja $1985 \mathrm{v}$ Portorožu dva dneva z minimalno temperaturo pod $-8{ }^{0} \mathrm{C}$, v Kubedu pa je bilo takih dni kar 11. Pod $-10{ }^{\circ} \mathrm{C}$ se v Portorožu temperature niso spustile, v Kubedu je bilo takih dni šest. Absolutna minimalna temperatura je bila ob tej pozebi v Portorožu $-9,3{ }^{0} \mathrm{C}(8.1 .1985)$, v Kubedu pa istega dne $-16{ }^{\circ} \mathrm{C}$. V Kubedu je bilo tako mraz tudi zaradi lege $\mathrm{v}$ podolju, kjer se je razvila temperaturna inverzija. Primerjava za zadnjo pozebo leta 1996 ni možna, ker po letu 1991 ne deluje več nobena meteorološka postaja $\mathrm{v}$ zaledju.

Verjetnost mrzlih dni (minimalna temperatura pod $0{ }^{0} \mathrm{C}$ ) in zelo mrzlih dni (minimalna temperatura pod $-10{ }^{\circ} \mathrm{C}$ ) je ob obali in v višji notranjosti po podatkih za obdobje 1961-1990 zelo različna. Ob morju povprečno v 30. letih ni niti enega zelo mrzlega dneva, v zaledju pa vsaj eden. Mrzlih dni je ob obali povprečno okoli 8 na leto, v notranjosti Slovenske Istre približno 30, na Krasu, v Vipavski dolini in Brdih pa od 30 do 45. Verjetnost, da se živo srebro spusti pod $-8{ }^{0} \mathrm{C}$, ko se pojavijo prve poškodbe oljk, je v notranjosti velika. V povprečju se take temperature pojavijo vsako drugo leto. Ob obali se to zgodi vsakih 15 let, kar je v okviru sprejemljivih (sedanjih) meja za ekonomsko gojenje oljk. Vprašanje pa je, kaj bo v prihodnje, ko bo proizvodnja olja zaradi širjenja nasadov in prihajanja $\mathrm{v}$ polno rodnost danes večinoma mladih nasadov večja in bo njegova cena, tudi zaradi vedno večjega uvoza, po vsej verjetnosti nižja. Nevarnost pozebe lahko nekoliko omilimo tudi s pravilnim izborom mikrolokacije nasada (prisojne lege $\mathrm{v}$ zatišju pred burjo $\mathrm{v}$ termalnem pasu), $\mathrm{s}$ pravilnim sortnim izborom in skrbnejšo lego.

Drugi klimatski elementi, razen burje, ki lahko s svojo močjo lomi veje in prispeva k nižanju temperatur, niso omejevalni dejavnik uspevanja oljk. Povprečno se na 30 let zgodi le enkrat, da oljke (teoretično) v poletnih mesecih trpijo zaradi suše, ko količina padavin ne preseže 50 do $70 \mathrm{~mm}$, kar je najmanj za zadostno rodnost. Za sušo so bolj občutljive mlade rastline, ki imajo slabše razvit koreninski sistem, zato jih je treba prva leta poleti ob večji suši zalivati. 
Tabela 1: Temperaturni pragovi za oljko in njihovo pojavljanje v Slovenski Istri v referenčnem obdobju 1961-1990.

\begin{tabular}{|c|l|c|c|}
\hline Temperatura & Vrsta poškodbe & \multicolumn{2}{|c|}{ Stevilo dni s temperaturo v 30 letih } \\
\hline do $-6{ }^{0} \mathrm{C}$ & Brez škode & Portorož $(92 \mathrm{~m})$ & Kubed $(262 \mathrm{~m})$ \\
\hline$-7 \mathrm{do}-9^{0} \mathrm{C}$ & $\begin{array}{l}\text { Poškodbe listov in mladih } \\
\text { poganjkov }\end{array}$ & 2 & 30 \\
\hline pod $-10^{\circ} \mathrm{C}$ & Poškodbe vejic & 0 & 2 \\
\hline pod $-15^{\circ} \mathrm{C}$ & Pozeba glavnih vej in debla & 0 & 1 \\
\hline nad $40 / 50^{\circ} \mathrm{C}$ & Prenehanje rodnosti & 0 & 0 \\
\hline
\end{tabular}

\section{POZEBE V PRETEKLOSTI}

Pozebe so v submediteranski Sloveniji stalnica, ki jo je potrebno upoštevati ( $v$ virih so dokumentirane predvsem pozebe oljk). Po kroniki izrednih vremenskih dogodkov, ki jo je za Trst, Istro, Kras in vzhodno Furlanijo sestavil za obdobje po 7. stoletju Braun (1935) in z dodatnimi viri dopolnil Ogrin (1994), je poročil, ki neposredno seznanjajo s pozebami oljk, skupaj s pozebami v 20. stoletju, 20 (tabela 2). Od tega jih bilo v zadnjih 300 letih 16, povprečno ena na vsakih 18 let.

Najpogostejše so bile v 18. stoletju (sedem - vsakih 14 let), še zlasti v njegovi drugi polovici. Te se skupaj s pozebami iz prve polovice 19. stoletja uvrščajo na konec t.i. male ledene dobe, sorazmerno hladnega obdobja, ki se je v Evropi začelo sredi 15. stoletja in je imelo več viškov ohladitev, enega tudi ob koncu obdobja.

Tabela 2: Pozebe oljk v preteklosti.

\begin{tabular}{|l|c|l|l|}
\hline Stoletje & Št. pozeb & Leto pozebe & Pogostost \\
\hline 15. & 1 & 1441 & \\
\hline 16. & 0 & & \\
\hline 17. & 2 & 1684,1685, & \\
\hline 18. & 7 & $1704,1709,1738,1763,1782,1789,1795$, & na 15 let \\
\hline 19. & 4 & $1820,1829,1847,1885$, & na 25 let \\
\hline 20. & 5 & $1901,1929,1956,1985,1996$, & na 20 let \\
\hline $15 .-20$. st. & 19 & & na 30 let \\
\hline
\end{tabular}

Po analogiji z drugo polovico 19. stoletja in 20. stoletjem, ko imamo hkratne klimatske meritve in opise posledic nizkih zimskih temperatur, lahko predvidevamo, da je bilo včasih pozeb še več. $Z$ veliko verjetnostjo lahko domne- 
vamo, da so oljke vsaj delno pozeble tudi v letih, ko so kronisti pisali o ledu v beneških lagunah, ob izlivu Soče ali obali Tržaškega zaliva. $Z$ upoštevanjem te domneve se v zadnjih 300 letih poveča pogostost pozebe na vsakih 14 let, $\mathrm{v}$ 18. stoletju pa na vsakih devet let.

20. stoletje velja $\mathrm{v}$ klimatski zgodovini za sorazmerno toplo obdobje, $\mathrm{s}$ postopnim zviševanjem temperatur, zlasti zimskih. V tem stoletju je bilo, vključno z zadnjo pozebo leta 1996, pet večjih zmrzali oljk (tabela 3). Povprečno so se pojavile na vsakih 20 let.

Tabela 3: Značilnosti pozeb oljk v Slovenski Istri v 20. stoletju.

\begin{tabular}{|c|c|c|}
\hline Pozeba & Absolutne minimalne temp. & Škoda \\
\hline 1929 & Trst (11.2): & Uničenih $90 \%$ dreves. \\
\hline 1956 & $\begin{array}{ll}\text { Koper (10.2): } & -12,8^{0} \mathrm{C} \\
\text { Kubed (16.2.): } & -14,6^{0} \mathrm{C}\end{array}$ & $\begin{array}{l}\text { Do tal pozeblo } 30 \% \text { oljk. } \\
\text { Pozeba zaustavila obnovo. }\end{array}$ \\
\hline 1985 & $\begin{array}{ll}\text { Portorož (8.1.): } & -9,3{ }^{0} \mathrm{C} \\
\text { Kubed (8.1.): } & -16,0{ }^{0} \mathrm{C}\end{array}$ & $\begin{array}{l}\text { Poškodovanih } 60 \% \text { dreves. } \\
\text { Pridelek manjši za } 80 \% \text {. }\end{array}$ \\
\hline 1996 & $\begin{array}{l}\text { Portorož (29.12.): }-8,5^{0} \mathrm{C} \\
\text { Korte (29.12.): } \quad-10,0{ }^{0} \mathrm{C}\end{array}$ & Skoraj v celoti prizadeti enoletni nasadi. \\
\hline
\end{tabular}

\section{NAPOVEDANE KLIMATSKE SPREMEMBE IN TOPLOTNO ZAHTEVNEJŠE KULTURE}

Vse več znanstvenikov je prepričanih, da bo 21. stoletje čas globalnih sprememb podnebja, katerih glavni krivec naj bi bil človek. Za napovedovanje bodočega podnebja se uporablja modele, ki pa zaenkrat ne dajejo najbolj zanesljivih napovedi. Po bolj optimističnih napovedih naj bi se povprečna temperatura na Zemlji v tem stoletju dvignila za $1,4{ }^{\circ} \mathrm{C}$, po bolj pesimističnih pa celo za $6{ }^{\circ} \mathrm{C}$. Na severni polobli, v višjih geografskih širinah in pozimi naj bi bilo ogrevanje izrazitejše. Klimatski scenariji za bodoče podnebje in z njim povezane spremembe $\mathrm{v}$ naravnem in družbenem okolju so še manj zanesljivi za posamezne manjše dele svete. Kljub temu je bila $\mathrm{z}$ upoštevanjem sprememb v splošni cirkulaciji zraka in dosedanjih trendov klimatskih elementov pri nas, izdelana napoved bodočega podnebja tudi za Slovenijo - tabela 4 (Prvo poročilo Konferenci pogodbenic Okvirne konvencije ZN o spremembi podnebja, 2001; tudi v Kajfež-Bogataj, 2001).

Za Slovenijo je zanesljivejša napoved temperatur, pri padavinah so razlike celo v predznaku. Ocenjujejo, da bodo v kmetijstvu višje temperature med drugim podaljšale vegetacijsko dobo in izboljšale razmere za gojenje toplotno 
zahtevnih rastlin. Za mediteranske kulture to pomeni potencialno razširitev dosedanjega areala, npr. oljke v višje predele Slovenske Istre, bolj intenzivno gojenje $\mathrm{v}$ Brdih in Vipavski dolini ter morda začetek oljkarstva v nižjih predelih Krasa. Višje temperature naj bi omogočile tudi širokopoteznejše gojenje kultur, ki se sedaj gojijo le v najbolj ugodnih mikrolegah, npr. mandarin. Žal pa utegnejo te pozitivne učinke izničiti negativni učinki spreminjanja podnebja. Pri mediteranskih kulturah ne v takšni meri večja ogroženost zaradi suše, saj so te kulture nanjo prilagojene, pač pa večja verjetnost vremenskih ujm vseh vrst, vključno s pozebami in spremembe povezane s pogostostjo in intenziteto napadov škodljivcev in bolezni. Tu lahko pri oljkah pričakujemo večje težave in stroške zaradi napadov oljčne muhe.

Tabela 4: Okvirni klimatski scenariji za Slovenijo za 21. stoletje.

\begin{tabular}{|l|l|l|l|}
\hline Obdobje & $\begin{array}{l}\text { Sprememba } \\
\text { temperature }\end{array}$ & $\begin{array}{c}\text { Sprememba } \\
\text { letne } \\
\text { količine } \\
\text { padavin }\end{array}$ & Opombe \\
\hline $\begin{array}{l}\text { Srednjeročno } \\
\text { (okoli leta 2025) }\end{array}$ & $+1{ }^{0} \mathrm{C} \pm 0,5{ }^{0} \mathrm{C}$ & $0 \% \pm 10 \%$ & $\begin{array}{l}\text { Intenzivnejše ogrevanje hladne } \\
\text { polovice leta, manj dni s snežno } \\
\text { odejo, manjši dnevni temperaturni } \\
\text { razpon, intenzivnejši nalivi, } \\
\text { spremenjen padavinski režim }\end{array}$ \\
\hline $\begin{array}{l}\text { Dolgoročno } \\
\text { (okoli leta 2075) }\end{array}$ & $+2,5{ }^{\circ} \mathrm{C} \pm 1{ }^{0} \mathrm{C}$ & $0 \% \pm 10 \%$ & $\begin{array}{l}\text { Pogostejši in intenzivnejši } \\
\text { ekstremni vremenski dogodki } \\
\text { (poplave, suše, neurja) }\end{array}$ \\
\hline
\end{tabular}

Vir: Prvo poročilo..., 2001; Kajfež-Bogataj, 2001

Za na mraz občutljive mediteranske kulture utegne biti zelo neugodna kombinacija podaljšanja vegetacijske dobe $\mathrm{v}$ jesenskem času oziroma zgodnejši začetek le-te spomladi ali celo ob koncu zime ter morebitna povečana pogostost vdorov hladnega zraka. Analize pozeb v 20. stoletju so namreč pokazale (Meze, 1995; Ogrin, 1997), da so bile oljke najbolj prizadete ravno tedaj, ko se je zaradi nadpovprečno toplih jeseni in zim vegetacija podaljšala in so oljke nepripravljene dočakale vdor hladnega zraka. Pri tem absolutna stopnja mraza niti ni bila toliko pomembna. Da bodo vdori hladnega zraka tudi ob predvideni splošni otoplitvi podnebja tako pogosti kot dosedaj, če ne pogostejši, je realno pričakovati, saj je za klimatske razmere $\mathrm{v}$ zmerno toplem pasu značilno, da so občasno pod vplivom tako toplih in vročih tropskih zračnih mas, kakor tudi hladih in mrzlih polarnih ali celo arktičnih mas. 
S tega vidika bi morali biti pri morebitnem širjenju arealov toplotno zahtevnejših kultur in vpeljevanju novih zelo previdni, ne glede na sedanje klimatske trende in napovedi. Izbirati bi morali topoklimatsko maksimalno ugodne lege ali pa se držati arealov in leg, ki jih je izluščila klimatska zgodovina zadnjega tisočletja, $v$ kateri so se izmenjevala tako toplejša, kakor hladnejša obdobja. V nasprotnem tvegamo zaradi pozeb še večjo materialno škodo, kakor smo ji priča v sedanjosti in s tem dražjo pridelavo.

Pri oljki je vztrajanje na tradicionalnem arealu smiselno tudi zaradi tega, ker je groba topoklimatska analiza Slovenske Istre pokazala (Lubi, 2001), da je znotraj njega še dovolj primernih površin za širitev te kulture. V analizi, ki je bila narejena na osnovi digitalnega modela reliefa $100 \times 100 \mathrm{~m}$ in programskega paketa IDRISI, so bile kot ugodne površine upoštevane nadmorske višine do $250 \mathrm{~m}$, nakloni do $37^{0}$ in južne ekspozicije. Razen višjih predelov in severnih leg so bile izločene tudi vse konkavne oblike reliefa, kjer so slabši klimatski in talni pogoji. Od celotne površine Slovenske Istre $419 \mathrm{~km}^{2}$ se je izkazalo kot primerne za oljčnike $20 \%$ oziroma $83 \mathrm{~km}^{2}$ (tabela 5, slika 3). Večja sklenjena območja primernih površin so obalno gričevje v zaledju Izole in Pirana, kjer je oljk tudi danes največ, Miljski polotok, pobočja nad desnim bregom Rižane, Badaševice in Dragonje ter prisoje pod črnokalsko kraško stopnjo. Če od nekaj več kot 8000 ha izločimo urbanizirane površine in površine, ki so tako ali drugače že zasedene, potem ostane za oljko na razpolago okoli 3000 ha, kar omogoča najmanj podvojitev sedanjih površin.

Tabela 5: Primernost Slovenske Istre za oljkarstvo z vidika topoklimatskih dejavnikov.

\begin{tabular}{|l|c|c|c|c|}
\hline \multirow{2}{*}{} & \multicolumn{2}{|c|}{ PRIMERNO } & \multicolumn{2}{c|}{ MANJ PRIMERNO } \\
\cline { 2 - 5 } & $\begin{array}{c}\text { Površina } \\
\left(\mathbf{k m}^{2}\right)\end{array}$ & Delež (\%) & $\begin{array}{c}\text { Površina } \\
\left(\mathbf{k m}^{2}\right)\end{array}$ & Delež (\%) \\
\hline Nadmorska višina (do 250m) & 226 & 54 & 193 & 46 \\
\hline Konkavnost & 345 & 83 & 73 & 17 \\
\hline Naklon (do 37 $7^{\mathbf{0}}$ & 397 & 95 & 22 & 5 \\
\hline Ekspozicija $\left(135-310^{0}\right)$ & 226 & 54 & 193 & 46 \\
\hline Skupno & $\mathbf{8 3}$ & $\mathbf{2 0}$ & $\mathbf{3 3 5}$ & $\mathbf{8 0}$ \\
\hline
\end{tabular}


Slika 2: Območja Slovenske Istre z ugodnimi topoklimatskimi pogoji za oljkarstvo.

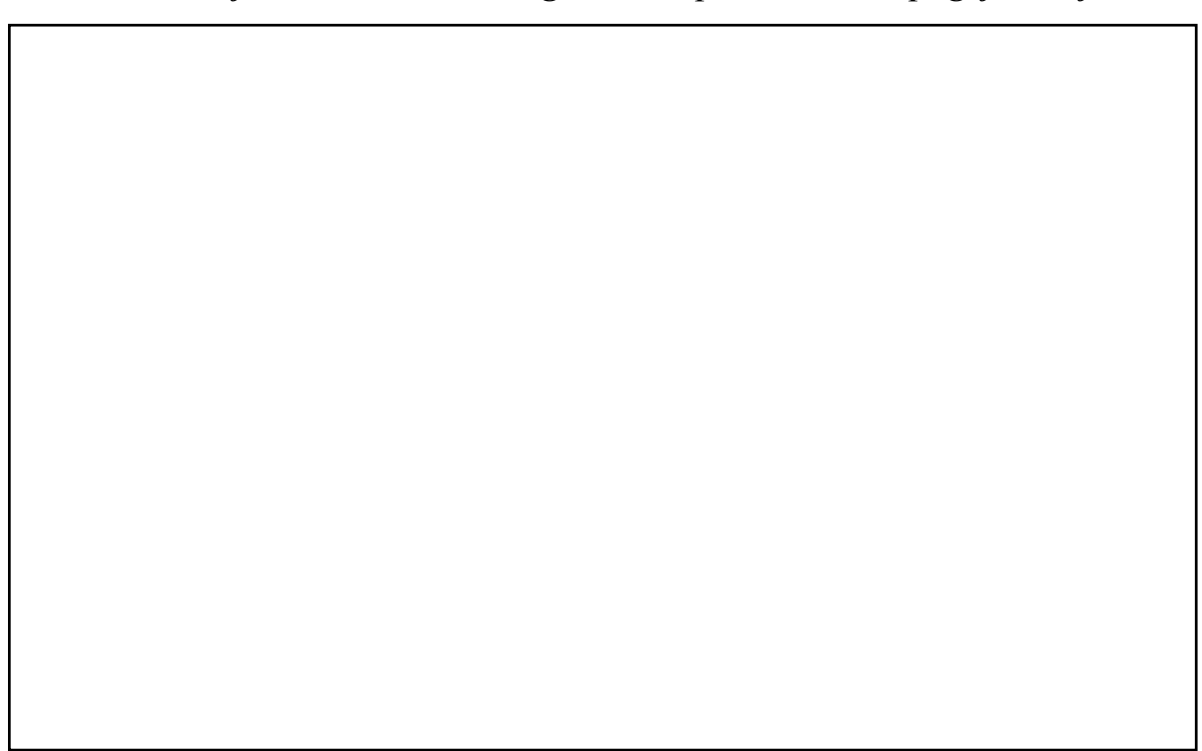

Slika 3: Območja primerna za rast in gojenje oljk..

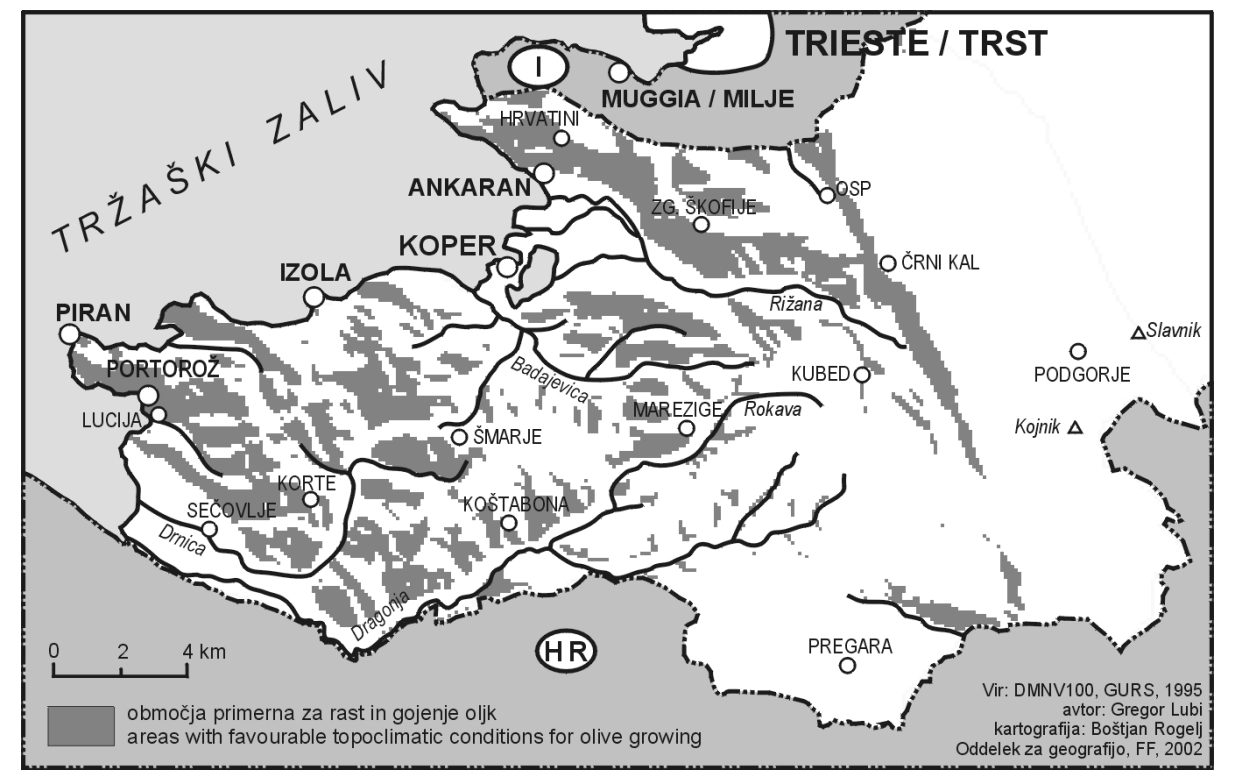




\section{SKLEPI}

Od vseh mediteranskih kultur je oljka najpomembnejša kultura v delu Slovenije, ki je pod vplivom submediteranskega podnebja. Oljkarstvo je predvsem v Slovenski Istri tradicionalna gospodarska panoga, ki je močno odvisna od klimatskih razmer, predvsem občasnih pozeb. Oljkarji se koristi in tudi perspektivnosti, še bolj pa tveganja pri ukvarjanju s to kulturo včasih premalo zavedajo. Na nevarnosti pozebe zato ni odveč še enkrat opozoriti, zlasti zato, ker se običajno govori, da se hujša pozeba ponovi na 25 do 30 let. Podatki za 20. stoletje, ki velja za sorazmerno toplo, kažejo, da so pozebe še pogostejše. Povprečno so bile vsakih 20 let. V hladnejših obdobjih, kakršno je bilo 18. stoletje, pa so bile še pogostejše - na 10 do 15 let.

$\mathrm{Na}$ prvi pogled gredo oljkarstvu na roke tudi klimatski trendi $\mathrm{v}$ zadnjih desetletjih in napovedi za 21. stoletje. Po nekaterih scenarijih naj bi se podnebje pri nas otoplilo, predvsem pozimi, za 1 do $2,5^{\circ} \mathrm{C}$. To teoretično pomeni tudi daljšo vegetacijsko dobo in primernejše temperaturne razmere za zahtevnejše kulture, tudi za oljko. Toda scenariji istočasno napovedujejo tudi povečano verjetnost ekstremnih vremenskih dogodkov, med njimi pozeb. Kombinacija obojega pa bi utegnila biti za oljke in ostale mediteranske kulture neugodna, saj so bile največje pozebe v 20. stoletju ravno tedaj, ko se je zaradi nadpovprečno toplih jeseni in zim vegetacija podaljšala in so oljke nepripravljene dočakale vdor hladnega zraka. S tega vidika bi morali biti pri širjenju teh kultur v bodoče zelo previdni, ne glede na sedanje klimatske trende in napovedi, in se držati zgodovinsko preverjenih arealov in lokacij. Za oljko se je pokazalo, da je znotraj tradicionalnega areala dovolj prostora za najmanj podvojitev sedanjih površin. V nasprotnem tvegamo zaradi pozeb še večjo materialno škodo in dražjo proizvodnjo, kar tržišče verjetno ne bo preneslo.

\section{Viri in literatura:}

Braun, G., 1935. Notizie meteorologiche e climatologiche della regione Giulia. Connsilio Nazionale della Ricercha, Comitato Nazionale per la Geografia, Roma, 80 str.

Digitalni model Slovenije 100 x 100 m (DMNV 100). Geodetska uprava Republike Slovenije.

Kajfež-Bogataj, L., 2001. Klimatske spremembe in njihove posledice - dejstva in predvidevanja. Gozdarski vestnik, Vol.59, št.4, Ljubljana, str.203-208.

Klimatografija Slovenije, 1995. Temperatura zraka 1961-1990. HMZ R Slovenije, Ljubljana, 356 str. 
Klimatografija Slovenije, 1995a. Padavine 1961-1990. HMZ R Slovenije, Ljubljana, 366 str.

Lubi, G., 2001. Analiza topoklimatskih dejavnikov za uspevanje oljk v Slovenski Istri. Seminarska naloga, Odd.za geografijo Filozofske fakultete, Ljubljana, 58 str.

Meze, D., 1959. Pozeba oljke v Primorju leta 1965. Geografski zbornik V (1959), Ljubljana, str.85-139.

Ogrin, D. 1994. Modern Age Climatic Fluctuations in the Area of the Gulf of Trieste. Geografski zbornik 34, Ljubljana, str.5-80.

Ogrin, D., 1995. Podnebje Slovenske Istre. Knjižnica Annales 11, Koper, 381 str.

Ogrin, D., 1997. Ob pozebi oljk v Slovenski Istri decembra 1996. Ujma 11, Ljubljana, str.34-38.

Prvo poročilo Konferenci pogodbenic Okvirne konvencije ZN o spremembi podnebja, 2001, MOP R Slovenije, Ljubljana, 91 str.

Razvoj pridelovanja in predelave oljk na območju Kopra, Izole in Pirana. Elaborat za potrebe projekta $\gg$ Razvoj proizvodnje in predelave oljk v Jugoslaviji«, Ljubljana, 1985.

Sancin, V., 1990. Velika knjiga o oljki. ZTT; Trst. 319 str.

Vesel, V., 1996. Oljkarstvo v Sloveniji. Sodobno kmetijstvo, let.29, št.9, Ljubljana, str.391-394.

Vesel, V., 1998. Oljkarstvo v Slovenski Istri. Glasnik ZRS Koper, let.3, št.5, Koper, str.51-60.

\section{FROSTS IN PRIMORSKA REGION FROM THE ASPECT OF CLIMATICALLY MORE SENSITIVE CULTURES}

\section{Summary}

In the south-west part of Slovenia whose landforms are open to the Trieste Gulf, or the Mediterranean, the climatic conditions are milder than in the regions in the inland of Slovenia. Mainly the higher temperatures (those in winter and autumn in particular) and the longest duration of insolation are of vital importance for the growth of climatically more sensitive cultures. General climatic characteristics are akin to the Mediterranean ones, so that some cultures that are typical of the central Mediterranean also grow here, e.g. olive, fig-tree, almond, pomegranate, etc. Due to the northern position, invasions of very cold air masses are also frequent, which can cause stronger or weaker frosts that also affect olives which are economically the most important Mediterranean culture in Slovenia. 
The analysis of historical records of damage by frosts (to olives in particular) from the 15 th cent. to the end of the 20th cent. showed that frosts in the submediterranean part of Slovenia were a recurrent phenomenon, because they occur irrespective of the general climatic situation of the period. In the 20th cent., which is considered to be one of the warmest centuries so far, frosts occurred every 20 years on average. In the 19th cent., when the so-called little ice age ended, their recurrence period was 25 years, and in the 18th cent., they occurred every 15 years, approximately. The average recurrence period of frosts in the last five centuries was 30 years. Every frost results in a rather great material damage and also exerts influence on the size of the area of olive growing. Thus, for example, after the frost of 1929, olive practically disappeared from the Goriška Brda region, where it began to make a comeback in the last decade only. Equally, olive is coming back again in greater numbers to higher parts of Slovenian Istria.

The climatic trends in the last decades, too, speak in favour of the development of olive growing and also of other climatically more sensitive cultures and so do the forecasts for the $21 \mathrm{st}$ cent. According to certain anticipations, the climate in our zone should warm up, in winter in particular, by 1 to $2,5^{\circ} \mathrm{C}$. Theoretically, this also means a longer vegetation period and more favourable temperature conditions for climatically more sensitive cultures and, possibly, also a greater choice of cultures (mandarin orange?). However, these anticipations concurrenty prognosticate an increased possibility of extreme weather events, frosts as well. A combination of both could be unfavourable for olives and other Mediterranean cultures, because the severest frosts in the 20th cent. occurred exactly at the time when the vegetation period was prolonged due to autumns and winters that were warm above average, so that olives were unprepared when the invasion of cold air began. In view of these facts, we should be very cautious in the future in planning the spread of climatically sensitive cultures, irrespective of the current climatic trends and forecasts, and should stick to historicaly tested areas and locations. Otherwise the risk of material damage because of frosts will be even greater. 